See discussions, stats, and author profiles for this publication at: https://www.researchgate.net/publication/337399350

\title{
EFFECTS OF INTRODUCING A PARAMETRIC CAD IN A FIRST YEAR COURSE IN ENGINEERING DEGREE REGARDING QUALITY OF TECHNICAL DRAWINGS
}

Conference Paper $\cdot$ November 2019

DOI: 10.21125/iceri.2019.1688

\section{CITATIONS}

0

4 authors:

Alba Roda-Sales

Universitat Jaume I

34 PUBLICATIONS 11 CITATIONS

SEE PROFILE

-

Verónica Gracia

Universitat Jaume I

57 PUBLICATIONS 130 CITATIONS

SEE PROFILE

Some of the authors of this publication are also working on these related projects:

Innovation and educational improvement View project

Characterisation of the healthy and pathological hand View project
READS

32

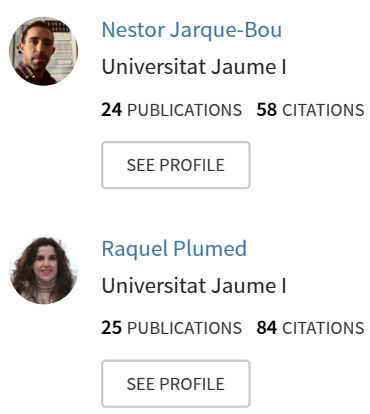




\title{
EFFECTS OF INTRODUCING A PARAMETRIC CAD IN A FIRST YEAR COURSE IN ENGINEERING DEGREE REGARDING QUALITY OF TECHNICAL DRAWINGS
}

\author{
A. Roda-Sales, N. Jarque-Bou, V. Gracia-lbáñez, R. Plumed \\ Department of Mechanical Engineering and Construction, Universitat Jaume I (SPAIN)
}

\begin{abstract}
The evolution of teaching in technical drawing during last years has been addressed towards new paradigms based on 3D modeling. Nevertheless, not only 3D modeling skills are important for an engineer, the ability to generate quality technical drawings also take part of the learning objectives and should therefore be included in the curriculum. For several years, the core subject of technical drawing at Universitat Jaume I has been a common subject during the first course of different Engineering bachelor's degrees (Mechanical, Industrial Technologies, Electrical, Chemical and Agrifood/Rural). However, in the last two years the subject in the case of Agrifood Engineering has been taught independently. This course, aiming for a more intuitive introduction to 3D modeling, the subject has experienced a general methodological change for all the degrees, except for the Agrifood Engineering one. Apart from changing the order of contents with the intention of improving spatial vision, the use of a different commercial CAD software was implemented, this being parametric.

In a previous work, the effect of this general methodological change was assessed through the academic performance regarding 3D modeling by comparing the scores before and after implementing the change, as well as through specific questionnaires addressed to students and teachers, obtaining very positive results. Notwithstanding, the effects of the change performed on the obtainment of technical drawings were not analyzed. Taking advantage of having two groups (the one that has experienced the change and the one that did not), they were asked to model and generate the drawing of the same parts in their final exams, with the aim of comparing the scores obtained when assessing their skills of modeling, but also in creating technical drawings (views, sections and dimensioning) and in the quality on technical drawings presentation (title block, line thickness, etc.). Scores were collected and statistical analyses were performed, bringing to light that despite the good results that were obtained in previous studies regarding the 3D modeling, teaching efforts in how to generate technical drawings with quality should be reinforced in future.
\end{abstract}

Keywords: Parametric CAD, Learning Experience, Teaching, Technical Drawing.

\section{INTRODUCTION}

CAD technologies are constantly evolving, and teaching in technical drawing has to do so accordingly. The tendency in last years has been going towards new paradigms based on 3D modeling, as it has been considered as a requirement for future engineers properly prepared [1]. For this reason, at Universitat Jaume I CAD 3D modeling has been introduced throughout last years in the first course subject of technical drawing. This subject used to be common to several Engineering bachelor's degrees (Agrifood Engineering, Mechanical Engineering, Industrial Technologies Engineering, Electrical Engineering and Chemical Engineering). Nevertheless, the last two years the Agrifood Engineering students were taught independently, as their necessities for their future application slightly differ from the others.

As a step further in this introduction of CAD 3D modeling, and aiming for a more intuitive introduction of it, a methodological change has been implemented this course in the subject for all the Engineering degrees, except for the Agrifood one. As the introduction of students to CAD 3D modeling in this subject has always been preceded by lessons on projection systems, what implied a particularly tough task for those students that lacked basic concepts on technical drawing or had more difficulties in spatial vision, this course the order has been swapped. Furthermore, the use of a different commercial CAD software was also implemented, as it was considered to ease modeling process owing to the fact that it was parametric. Despite AutoCAD ${ }^{\circledR}$ (which has been the software used in the subject during last years) is one of the most powerful tools to create engineering drawings, it has a 3D module that is not as intuitive as others from parametric CAD software, such as SolidWorks ${ }^{\circledR}$ (which was the implemented one). 
The effect of these changes on students' academic performance has already been assessed in a previous work [2], where scores before and after implementing the changes were compared. The scores compared comprised those obtained in the modeling section of the exam, as well as those assessing the theoretical part of the subject. Furthermore, both students and teachers were asked to answer specific questionnaires regarding their perception towards methodological change benefits, as well as software usability aspects regarding the non-parametric one (used in past courses) and the parametric one (recently implemented). This study revealed that the change contributed to a better students' academic performance. Moreover, both the methodological change and the software change were positively rated by students and teachers, encouraging teachers to follow in this direction. Nevertheless, although the results from this work revealed a positive effect on all the aspects assessed, the effects of the change on technical drawings generation were not studied.

Despite the raising of CAD 3D modeling during last decade, let us not forget the importance of generating quality technical drawings, as they are the universal engineering language. For this reason, generating technical drawings following the adequate standards and ensuring comprehension of the information it contains is a basic skill that engineers should acquire during their training years. For this reason, the main purpose of this study is to assess the impact of the change performed but in this case paying special attention to their technical drawing generation skills. Results are tested through students' academic performance, but rather than comparing academic performance regarding past course, taking advantage of having two student groups, one using AutoCAD ${ }^{\circledR}$ as traditionally, and the other using SolidWorks ${ }^{\circledR}$ and having gone through the methodological change. They were asked to perform the same tasks with the aim of comparing scores regarding technical drawings. Therefore, in this study, a score comparison between the student group that experienced the change (Mechanical Engineering, Industrial Technologies Engineering, Electrical Engineering and Chemical Engineering) and the one that did not (Agrifood Engineering) is performed.

\section{METHODOLOGY}

\subsection{Subjects}

The study was conducted taking into account scores obtained by a total of 167 first course engineering students, which were divided into two main groups: group A (17 students) and group B (150 students). Group A was composed of Agrifood Engineering students, who did not experience a subject methodological change and used AutoCAD ${ }^{\circledR}$ software. Group B was composed of Mechanical Engineering, Industrial Technologies Engineering, Electrical Engineering and Chemical Engineering students, who experienced a subject methodological change and used SolidWorks ${ }^{\circledR}$ software.

\subsection{Experiment}

Students of both groups were asked to model and generate technical drawings of the same parts in their final exams. The part proposed to be modeled was presented to students of both groups using top, front and profile views, and also partial sections (Fig. 1). The modeling of this part required using a variety of operations that both groups have seen in their respective classes with the same level of detail. Both groups were given the same part dimensions and other considerations (e.g.: drill metrics). 

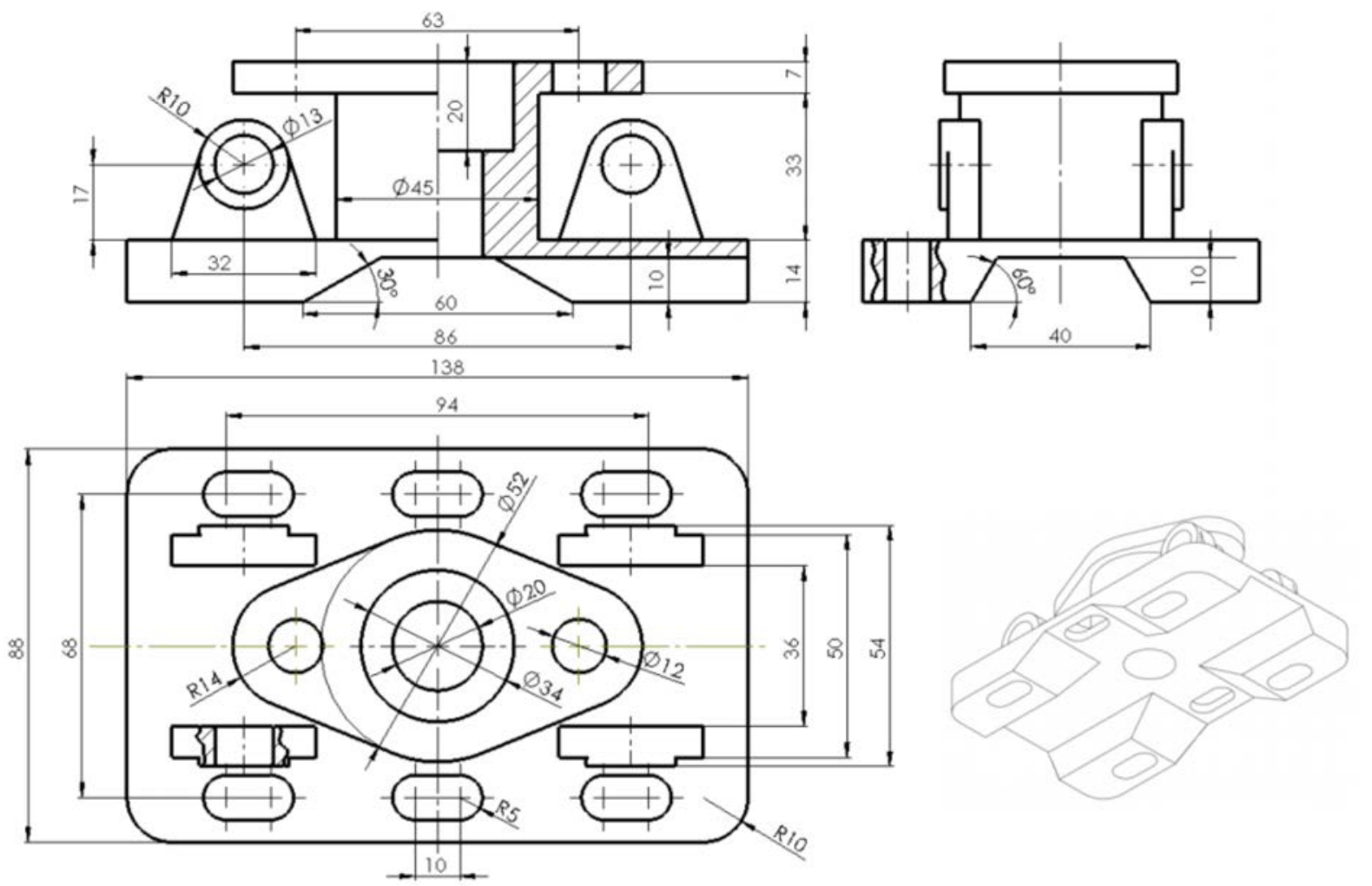

Figure 1. Part that students were asked to model.

The part they were given to generate the technical drawing consisted of a part previously modeled by subjects' teachers, which could be downloaded from the university website by students (Fig. 2). The generation of the technical drawing of this part required the application of some concepts also seen in class by both groups with the same level of detail.
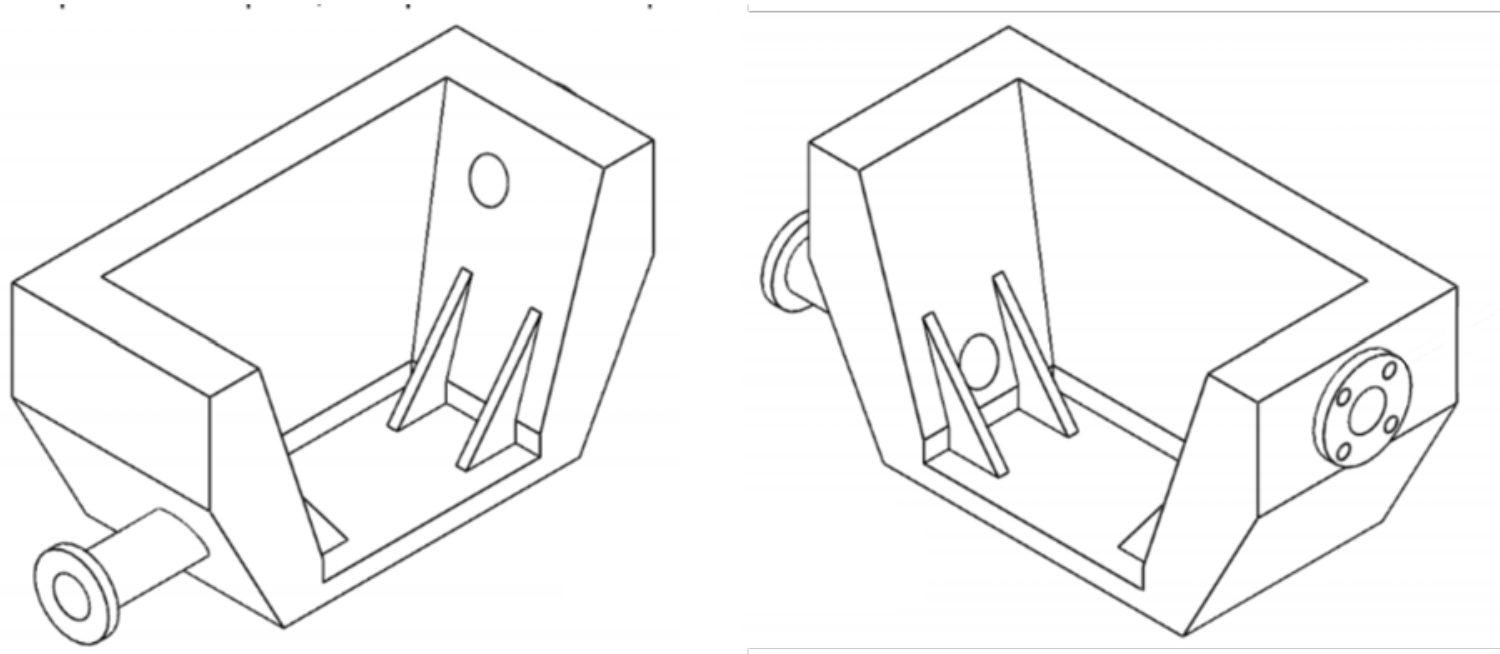

Figure 2. Modelled part from where students were asked to generate the technical drawing.

\subsection{Data analysis}

\subsubsection{Scoring criteria}

The same scoring criteria was used during the correction of exams from both groups. One of the teachers corrected exams from both groups verifying this point. Even though in each of the exercises there are many aspects to be corrected, for the sake of simplicity the scores have been clustered in 
only two sections for statistical comparison purposes. The modeling section score took into account each of the operations required to model the part, as well as quality of sketches to perform each one, dimensions adequacy, drill metrics adequacy or usage of operation symmetry or matrix, among others. Score from all these aspects was considered as a unique section. The section corresponding to technical drawings was also considered in only one score. Nevertheless, in a second phase, for the sake of delving into the technical drawings accuracy, scoring of technical drawing section was divided into two subsections: adequacy of technical drawing (which took into account several aspects as proper selection of views and sections, as well as dimensioning) and presentation quality (which evaluated aspects as line thickness, title block, etc.).

\subsubsection{Statistical analysis}

In order to compare scores obtained in each of the aspects assessed, all scores obtained from each subpart were scaled from $0-10$, as the weight in their final tests was not the same among groups (both groups had other sub-sections in their respective exams).

In the first phase, descriptive data of the two sections' scores per degree was obtained and, after checking normality using Kolmogorov-Smirnov, the proper statistics analysis was performed to check if there were significant differences depending on the software used. In the second phase, the Technical Drawing section was divided into two sub-sections regarding the adequacy of the selection of views and sections along with dimensioning and the presentation quality. Again, after checking normality, the proper statistics analysis was performed to check if there were significant differences depending on the software used for each sub-section.

\section{RESULTS}

Table 1 shows mean scores and standard deviation (SD) for both sections: Modeling and Technical Drawing. Kolmogorov-Smirnov over score distributions on each section depending if software used was AutoCAD or SolidWorks showed normality in Modeling scores but no in Technical Drawings' scores. Results of the ANOVA over scores (factor: software used) showed no significant differences for the Modeling section. $U$ test from Mann-Whitney showed also no significant differences in Technical Drawings scores between Agrifood Engineering and the rest of Engineering.

Table 1. Mean scores (SD) obtained in each section.

\begin{tabular}{l|c|c}
\hline \multicolumn{1}{c|}{ Degree } & Modeling & $\begin{array}{c}\text { Technical } \\
\text { Drawing }\end{array}$ \\
\hline Agrifood Engineering & $6.90(2.22)$ & $5.75(2.42)$ \\
\hline Electrical Engineering & $5.88(2.19)$ & $4.69(3.56)$ \\
\hline Mechanical Engineering & $6.50(2.11)$ & $5.16(3.39)$ \\
\hline Chemical Engineering & $5.75(2.52)$ & $4.69(3.77)$ \\
\hline $\begin{array}{l}\text { Industrial Technologies } \\
\text { Engineering }\end{array}$ & $6.38(2.01)$ & $5.23(3.42)$ \\
\hline \hline
\end{tabular}

Table 2 shows mean scores in each sub-section of Technical Drawing. Kolmogorov-Smirnov over score distributions on each sub-section depending if software used was AutoCAD or SolidWorks showed no normality. Results of applying $U$ test from Mann-Whitney showed no significant differences for Presentation Quality, but significant differences for Adequacy of technical drawing. $(p<0.05)$. 
Table 2. Mean scores (SD) obtained in each Technical Drawings sub-section.

\begin{tabular}{l|c|c}
\hline \multicolumn{1}{c|}{ Degree } & $\begin{array}{c}\text { Adequacy of } \\
\text { technical drawing }\end{array}$ & $\begin{array}{c}\text { Presentation } \\
\text { Quality }\end{array}$ \\
\hline Agrifood Engineering & $4.56(1.45)$ & $6.94(2.62)$ \\
\hline Electrical Engineering & $2.23(2.08)$ & $7.15(2.98)$ \\
\hline Mechanical Engineering & $2.97(2.44)$ & $7.35(2.72)$ \\
\hline Chemical Engineering & $2.44(2.79)$ & $6.94(3.26)$ \\
\hline Industrial Technologies Engineering & $3.02(2.31)$ & $7.44(2.90)$ \\
\hline \hline
\end{tabular}

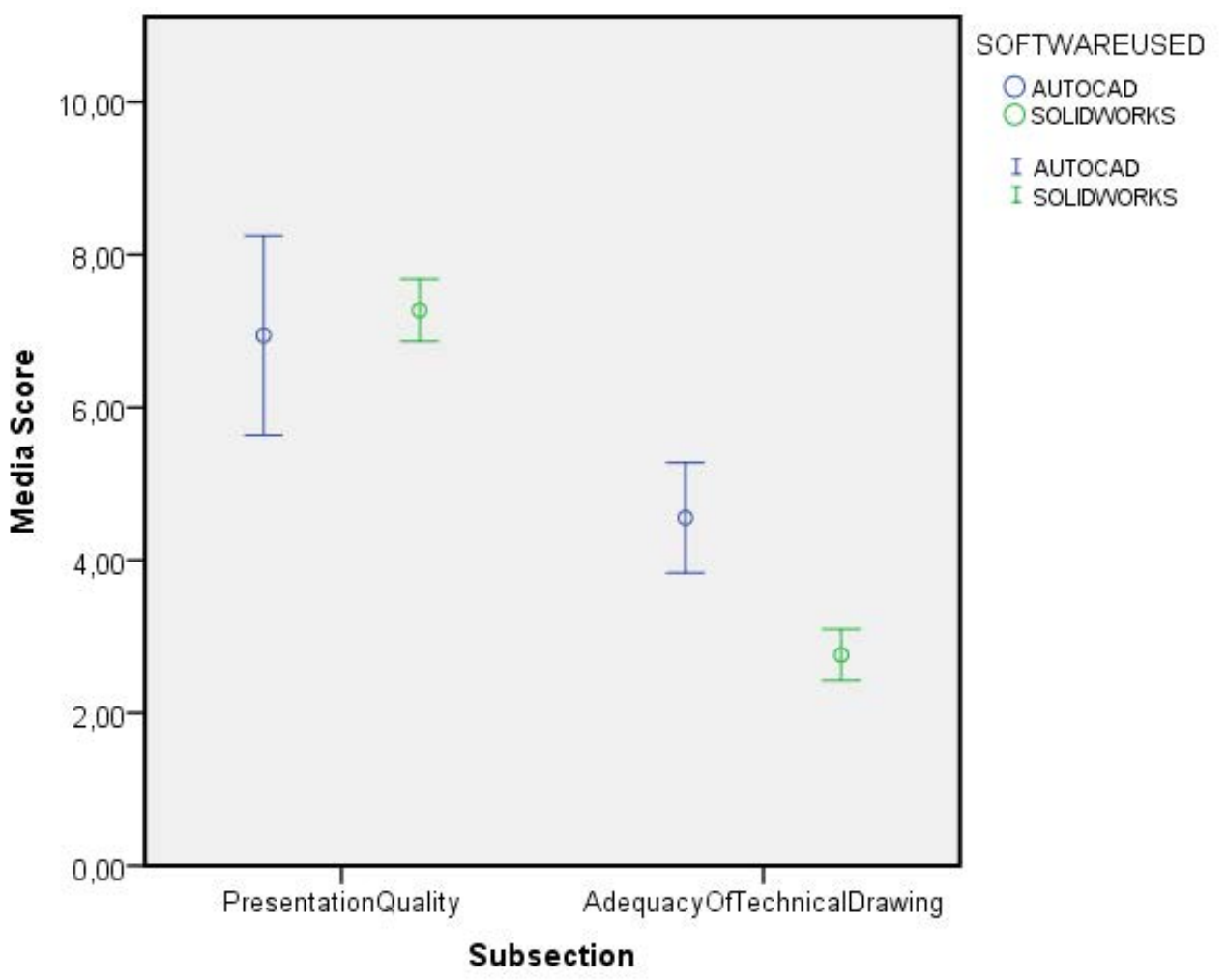

Figure 3. 95\% Confidence interval of mean score of the Technical Drawing sub-sections depending on the software used.

\section{CONCLUSIONS}

From the results, it can be observed that despite the good results obtained in previous studies regarding the 3D modeling when comparing scores with previous years, the comparison with Agrifood Engineering does not show better results in modeling with parametric software. However, there are other aspects not taken into account as a certain subjectivity introduced in the correction by different teachers. Even though same correction criteria was applied, the development of rubrics would be a good point to be taken into consideration in the future. Rubrics in this area are normally more focused on 3D models quality [3], [4], but evaluating criteria useful for students in all sections, especially regarding technical drawing should be developed. Benefits of using rubrics are proven, as they provide clear criteria facilitating feedback and self-assessment [5].

In the first phase, it seemed that no differences were found in Technical Drawings due to the new software used. However, when dividing into two sub-sections it was shown no differences in presentation quality, but statistical differences were found in the selection of the proper views, sections and dimensioning to completely and adequately represent the part in a Technical Drawing. Students were listened to in reference to the methodology change performed [6], [7] and good perceptions were obtained. Nevertheless, the selection of views, sections and dimensioning for properly define 
completely the part, lead to scores significantly lower than the Agrifood Engineering Degree. But what is more noticeable is the lower marks in this sub-section in all degrees. Increasing efforts have to be performed in the future in teaching how to generate adequate technical drawings. Results may be improved keeping the level of demand [8] but methodological changes must be still performed.

\section{ACKNOWLEDGEMENTS}

The research work reported here was made possible by the Innovative Education Project titled "Aprofundiment en conceptes de modelatge 3D parametric" given by USE - Universitat Jaume I.

\section{REFERENCES}

[1] X. Ye, W. Peng, Z. Chen, and Y.-Y. Cai, "Today's students, tomorrow's engineers: an industrial perspective on CAD education," Comput. Des., vol. 36, no. 14, pp. 1451-1460, Dec. 2004.

[2] A. Roda- Sales, V. Gracia-lbáñez, M.-J. Agost-Torres, M. Gómez-Fabra Gómez, and M. Núñez García, "Implantación de un CAD paramétrico en primer curso de ingeniería: un caso práctico," in 29 Congreso Internacional de Ingeniería Gráfica INGEGRAF, 2019.

[3] P. Company, M. Contero, J. Otey, and R. Plumed, "Approach for developing coordinated rubrics to convey quality criteria in MCAD training," Comput. Des., vol. 63, no. C, pp. 101-117, Jun. 2015.

[4] C. González-Lluch, P. Company, M. Contero, J. Dorribo Camba, and J. Colom, "A case study on the use of model quality testing tools for the assessment of MCAD models and drawings," Int. $J$. Eng. Educ., vol. 33, no. 5, pp. 1643-1653, 2017.

[5] A. Jonsson and G. Svingby, "The use of scoring rubrics: Reliability, validity and educational consequences," Educ. Res. Rev., vol. 2, no. 2, pp. 130-144, Jan. 2007.

[6] V. Gracia-lbáñez and M. Vergara, "Applying action research in CAD teaching to improve the learning experience and academic level," Int. J. Educ. Technol. High. Educ., vol. 13, no. 1, p. 9, Feb. 2016.

[7] M. Vergara and V. Gracia-lbáñez, "Action Research: When the teacher listens to the student. An experience in CAD teaching," in 5th International conference on education and new learning technologies (EDULEARN), 2013.

[8] V. Gracia-Ibáñez, M. Vergara, J. Chesa Sanchis, and S. Mondragón Donés, "Methodologies to improve academic results even when increasing the level of demand: an experience in cad teaching," in International Congress on Education, Innovation and Learning Technologies (ICEILT), 2014. 